\title{
Eficiência e Convergência da Inovação: um Estudo do Progresso Tecnológico para Países Desenvolvidos e em Desenvolvimento
}

\author{
Efficiency and Convergence of the Innovation: a Study \\ of Technological Progress for Developed and Developing \\ Countries
}

\author{
Frederick Fagundes Alves* \\ Soraia Araújo Madeira** \\ Lucas Vitor de Carvalho Sousa***
}

Resumo: Essa pesquisa visa analisar os níveis de eficiência técnica para países desenvolvidos e em desenvolvimento na geração de progresso científico e tecnológico para os anos de 2000 e 2010. Mais especificamente, pretende-se verificar a produtividade total dos fatores (PTF) por meio do índice de Malmquist e mensurar a convergência da eficiência dos países para grupos mais eficientes através do data envelopment analysis (DEA) e cadeias de Markov. Os resultados mostram que grande parte dos países é ineficiente tecnicamente no período analisado e aproximadamente $61 \%$ apresentaram aumento na produtividade, sendo que as mudanças no processo produtivo de uma mesma tecnologia foram mais expressivas. Pode-se notar que mais da metade dos países convergirão para a classe mais eficiente em gerar progresso científico e tecnológico. Conclui-se que não necessariamente os países mais desenvolvidos serão os mais eficientes e produtivos em gerar progresso científico e tecnológico.

Palavras-chave: Eficiência técnica. Sistema nacional de inovação. Convergência.

\begin{abstract}
This paper aims to analyze the technical efficiency levels for developed and developing countries in generating scientific and technological progress for the years 2000 and 2010. More specifically, we intend to analyze the total factor productivity (TFP) through Malmquist index and measure the convergence efficiency of countries for more efficient groups through the data envelopment analysis (DEA) and Markov chains. Most countries were technically inefficient in the analyzed period and approximately $61 \%$ of those had increased productivity, and changes in the production process of the same technology were more significant. We noticed that more than half of the countries converge to the most efficient in generating class scientific and technological progress. We conclude that not necessarily the most developed countries will be the most efficient and productive in generating scientific and technological progress.
\end{abstract}

Keywords: Technical efficiency. National system of innovation. Convergences.

\footnotetext{
* Doutor em Economia Aplicada pela Universidade Federal de Viçosa (UFV). Professor adjunto no Departamento de Contabilidade da Universidade Federal do Pará (UFPA). E-mail: frederickalves@gmail.com

* Doutora em Economia Aplicada pela Universidade Federal de Viçosa (UFV). E-mail: soraiamadeira@gmail.com

*** Doutor em Economia pela Universidade de Brasília (UnB). E-mail: lucasvitor.cs@gmail.com
} 


\section{1 lntrodução}

A economia dos Estados Unidos se destaca por ser uma das mais competitivas do mundo, alcançando liderança tecnológica em diversos ramos, sendo o país que mais produz artigos científicos, além de liderar o ranking de patentes mundiais e estar em terceiro lugar em termos dos gastos com pesquisa e desenvolvimento (PEDD) em proporção ao PIB no mundo (SANTOS, 2014).

Apesar da extensa discussão teórica sobre o progresso da ciência e da tecnologia em gerar crescimento e desenvolvimento para as nações, pouco se tem verificado quais são, de fato, os países que apresentam melhores desempenhos em produzir inovação. Muitos estudos abordam temas como o sistema nacional de inovação (SNI) e suas peculiaridades, os efeitos externos causados pela transferência de conhecimento, além de formas de fomentar o processo inovativo.

A partir disso, a presente pesquisa tem como intuito responder: os países mais desenvolvidos alocam seus insumos de maneira mais eficiente ao ponto de serem mais produtivos para gerar progresso científico e tecnológico?

Para responder tal questionamento, têm-se como objetivos: a) analisar a eficiência técnica dos países em gerar progresso tecnológico, mais precisamente publicação de artigos e concessão de patentes; b) mensurar a produtividade alcançada pelos países; c) verificar se há convergência das eficiências dos países para grupos mais eficientes e o tempo gasto para se chegar ao estado estacionário.

Através da aplicação de questionários, Guan et al. (2006) utilizam um modelo de análise de eficiência (data envelopment analysis - DEA) e mensuram que 16\% de 182 indústrias inovadoras na China estavam sobre a fronteira de eficiência. Já Diaz-Balteiro et al. (2006) utilizam um modelo de segundo estágio para verificar o relacionamento entre a eficiência produtiva e a atividade inovativa em empresas madeireiras da Espanha. No primeiro estágio, os autores verificaram a eficiência do setor econômico e financeiro através do DEA e, no segundo estágio, através de uma regressão logística, os autores exploraram o relacionamento entre a eficiência e indicadores da atividade inovativa e inferiram que não houve ligação significante entre a eficiência das madeireiras e a atividade inovativa.

Pan, Hung e Lu (2010) mensuram a eficiência técnica do SNI de 33 países da Ásia e da Europa e indicam que a ineficiência técnica da atividade inovativa nesses países é devida às ineficiências técnicas puras maiores que as ineficiências de escala, enquanto que Hashimoto e Haneda (2008) mostram que a produtividade de PED da indústria farmacêutica japonesa piorou ao longo do período de 1983 a 1992 devido à mudança da eficiência em PËD. 
Como contribuição, o presente artigo analisa a produtividade dos países em gerar artigos e patentes, através do índice de Malmquist (IM), levando em consideração os principais componentes que afetam essa produtividade (mudança de eficiência e/ou mudança tecnológica). Além disso, através da eficiência dos países para os anos de 2000 e 2010, são utilizadas cadeias de Markov com o intuito de verificar se há convergência dos países para o estado estacionário e mensurar o tempo gasto para que atinjam esse equilíbrio de longo prazo. Para isso, este trabalho faz uso de variáveis como: pesquisadores em PEBD (por milhão de habitantes) e gastos com pesquisa e desenvolvimento (por milhão de habitantes) como insumos (inputs); e como produtos (outputs), a média anual do número de artigos publicados em revistas internacionais por milhão de habitantes e a média anual do número de patentes.

Este trabalho está dividido em mais quatro seções, além desta introdução: a segunda seção apresenta o referencial teórico que aborda o SNI desenvolvido pela teoria neoschumpeteriana; a terceira seção abarca a metodologia de DEA, o IM e a convergência através de cadeias de Markov, que são utilizados para se atingir os objetivos e responder o problema da presente pesquisa; a quarta seção apresenta os resultados alcançados; e, por fim, a quinta seção traça as considerações finais deste trabalho.

\section{Referencial Teórico}

A definição de inovação está intimamente relacionada à formação de um novo conhecimento ou de novas combinações de conhecimentos disponíveis e transformados em produtos ou processos economicamente significantes. O ambiente, os atores e as instituições envolvidas nesse processo de produção do novo conhecimento esclarecem o conceito de um sistema de inovação (ALVES; TOYOSHIMA; TORRES, 2014).

O conceito básico de inovação decorre da obra Système national d'économie politique, de 1841, construído por Friedrich List, em que há uma tentativa de esclarecer o processo de catching up da Alemanha sobre a Inglaterra e o caso dos países em desenvolvimento. Conforme Gordon (2009), List antecipou ideias contemporâneas sobre o SNI, incluindo a importância da acumulação tecnológica. Mais tarde, Joseph Schumpeter foi o teórico que se tornou referência para a formulação do conceito de SNI, destacando a grande importância da inovação como motor do capitalismo.

Entretanto, segundo Gordon (2009), Christopher Freeman pode ser considerado o pai da teoria atual sobre inovação, já que expande o conceito de SNI, antes restrito a um tripé de instituições (governo/universidade/empresa), tendo a ciência como principal elemento de inovação. Freeman (1987), ao avaliar o siste- 
ma nacional japonês, ressalta as políticas sociais radicais de longo prazo adotadas por esse país, das quais se têm: PẺD; melhorias na educação e laboratórios para desenvolver habilidades e capacitações; forte produção e importação de novas tecnologias; formação de engenheiros; e proximidade entre o governo e o setor privado. Segundo Albuquerque (2004), esse estudo mais amplo sobre SNI envolve firmas e suas redes de cooperação e interação, universidades e institutos de pesquisas, instituições de ensino, sistemas financeiros, sistemas legais, mecanismos mercantis e não mercantis de seleção, governos e mecanismos e instituições de coordenação.

De acordo com Alves, Toyoshima e Torres (2014), todo esse sistema interage e cria processos de "ciclos virtuosos". Por isso, é necessário apoiar-se na teoria para entender o papel de cada instituição no aprimoramento de um conceito mais amplo de SNI. Anteriormente, o desenvolvimento era restringido a um modelo simplista, com um fluxo circular estático e em equilíbrio entre universidades e empresas, sendo o governo apenas um ator regularizador dessa cadeia movida pela ciência, perdendo espaço para mercados em que a inovação é o principal meio para dinamização e diferenciação do mercado.

A inovação, segundo a teoria neoschumpeteriana, é resultado da interação entre várias instituições. Esse conceito não se restringe somente à tecnologia per se, podendo ser também o progresso técnico em processos, produtos, organizações, marketing, etc. Além disso, não se restringe apenas ao locus empresarial, podendo ser o sistema do mercado local, nacional ou internacional.

A ideia de SNI ampliado destaca as relações e cooperações entre os agentes, sendo que as trocas de informações entre pessoas e organizações para a construção de um ambiente inovativo assumem um papel muito relevante. No entanto, muitas vezes, esse conhecimento adquirido não é difundido facilmente, dado que é utilizado como estratégia e domínio dentro do sistema capitalista.

Como destaca Romero e Jayme Júnior (2009, 2012), o processo de desenvolvimento deve ser estudado, de forma individual e única, para cada nação, pois depende de sua composição histórica, social, cultural, educacional, etc. Assim, a implantação de novas políticas para a concepção de um SNI deve ser adaptada, respeitando as peculiaridades de cada país e a heterogeneidade da estrutura produtiva e inovativa de cada região. Nessa direção, o conceito de SNI está ligado a um conjunto de características e relações socioeconômicas que um país/região deve possuir para empreender atividades de inovação e/ou imitação tecnológica.

Um SNI abrangente, conforme Freeman (1995), Nelson (1993) e Lundvall (1992), engloba tanto o processo de imitação tecnológica, e, posteriormente, sua difusão, quanto o processo de "empréstimo tecnológico", capacitação de inovação dessa tecnologia e, em seguida, a difusão desse conhecimento. Não existe 
um único SNI, já que dependente da evolução histórica e social de cada país ou região.

Seguindo isso, algumas características podem ser observadas em países cujo SNI é considerado eficiente. Há duas características principais: a primeira consiste num sistema educacional de qualidade e com amplo acesso à população, com o intuito de que haja profissionais capacitados para o avanço científico e a realização de inovações incrementais; a segunda é o enfrentamento de um trade-off entre especialização e adaptação. Nações com elevados níveis de especialização dificilmente se adaptarão às tecnologias de longo prazo, pois sempre estarão inovando em relação à tecnologia já existente.

Em um arcabouço neoschumpeteriano, tem-se evidente a relação entre o aumento da produtividade e o desenvolvimento da inovação. No entanto, essa relação é expressa por vários elementos estratégicos relacionados com a inovação, principalmente a relação entre os fatores de produção necessários ao processo de inovação com as instituições que são fundamentais para uma inovação bem-sucedida. Tal relação pressupõe a identificação de cada instituição relacionada com o processo de inovação.

A introdução de inovações em setores estratégicos de países e empresas gera aumento da produtividade, e o aumento da produtividade leva a novos investimentos em inovação. De acordo com Alves, Toyoshima e Torres (2014), esse processo de causalidade entre produtividade e inovação se mostra interdependente. Os ganhos de produtividade advindos de fatores externos, como acordos internacionais, comércio, aumento da escala de produção, entre outros, impactam de maneira positiva na exploração de novas inovações e tecnologias.

Segundo Carvalho e Avellar (2014), há uma concentração nos fatores determinantes da inovação (input para inovação) e nas consequências da inovação sobre os agentes econômicos, ou como o produto (output) da inovação gera vantagens, como uma maior produtividade. Nesse sentido, os modelos schumpeterianos buscam identificar os fatores específicos de aprendizado e interação entre os agentes com os fatores de inovação presentes na produção do conhecimento desses agentes. Por esse raciocínio, o aumento da produtividade não passa apenas pelo maior acúmulo de capital, mas, principalmente, pelo aprendizado tecnológico e ampliação da capacidade de inovação que variam entre os agentes.

Para Pan, Hung e Lu (2010), o esforço que um país exerce para inovar deve ser considerado dentro de um contexto de SNI. Esse esforço inovativo promoverá o desenvolvimento e melhorará a produtividade da economia. Portanto, na presença da produtividade em inovação atribuível ao processo de transformação, os países se tornarão mais eficientes e gerarão produtos mais competitivos. 


\section{Metodologia}

Como forma de mensurar a eficiência técnica do progresso científico e tecnológico dos países para os anos de 2000 e 2010, utilizou-se a metodologia de análise envoltória de dados (DEA). O uso dessa metodologia permite encontrar a eficiência de cada país em desenvolver progresso científico e tecnológico de maneira individualizada, considerando a atuação dos demais países em estudo e permitindo que a alocação dos insumos seja efetuada de forma a maximizar a eficiência em gerar produtos.

Com o intuito de verificar a evolução da eficiência ao longo do tempo, fez-se uso do IM, que são extensões dos modelos clássicos que permitem considerar técnicas não paramétricas em DEA sob circunstâncias dinâmicas. Além disso, através de matrizes de transições, utilizou-se o método de cadeias de Markov para se verificar se há convergência no longo prazo para países mais eficientes em maiores publicações de artigos e concessões de patentes.

\subsection{Análise Envoltória de Dados}

Os modelos de DEA são métodos não paramétricos baseados em uma amostra de dados observados de diferentes unidades produtoras, também conhecidas como unidades tomadoras de decisão (decision making units - DMUs). Essas DMUs consomem os mesmos insumos (inputs) para produzir os mesmos produtos (outputs). O objetivo é construir um conjunto de referências a partir dos próprios dados das DMUs e, então, classificá-las em eficientes ou ineficientes, tendo como referencial essa superfície (FERREIRA; GOMES, 2009).

Uma diferença entre as DMUs está nas quantidades consumidas e produzidas por cada uma. Uma determinada DMU será eficiente se, comparativamente às outras, tiver maior produção para quantidades fixas de insumos (orientação produto) e/ou se utilizar menos insumos para produzir uma quantidade fixa de produtos (orientação insumo). Ao estabelecer as DMUs com as melhores práticas produtivas, a DEA estima uma fronteira de possibilidades de produção, em que o nível de eficiência varia de 0 a 1 , ou de 0 a $100 \%$, dependendo da distância da DMU e a fronteira (LOBO; LINS, 2011).

As DMUs eficientes, ou seja, com eficiência de $100 \%$, estarão sobre a fronteira de possibilidades de produção. Porém, mesmo estando sobre a fronteira, essas DMUs ainda devem respeitar o princípio de Pareto-Koopmas, em que só serão realmente eficientes aquelas unidades em que não é possível diminuir nenhum insumo, ou aumentar qualquer produto, sem que se tenha que aumentar concomitantemente outro insumo, ou diminuir outro produto (COOPER SEIFORD; TONE, 2007). 
A técnica DEA, por ser considerada uma medida comparativa, não impõe o uso de formas funcionais e nem a estimativa de parâmetros para a construção da fronteira de possibilidades de produção. Logo, a DEA se configura como uma metodologia não paramétrica. Isso possibilita que, em uma mesma estimativa, insumos e produtos possuam unidades de medida diferentes e sem a necessidade de correção monetária, no caso de valores.

De acordo com Coelli et al. (2005), existem dois modelos clássicos de DEA: o modelo de retornos constantes à escala (constant returns to scale - CRS), proposto por Charnes, Cooper e Rhodes em 1978, conhecido também por CCR em homenagem aos autores; e o modelo de retornos variáveis à escala (variable returns to scale - VRS), proposto por Banker, Charnes e Cooper em 1984, também conhecido como BCC.

No modelo CCR, ocorre uma variação proporcional dos produtos em função da alteração de insumos em todos os níveis de escala, ou seja, pressupõe-se que as unidades produtivas estão operando em escala ótima. Já no modelo BCC, assume-se a não proporcionalidade entre insumos e produtos e admite-se a decomposição da eficiência técnica em eficiência pura e eficiência de escala. Como esclarece Lobo e Lins (2011), em um cenário com poucos recursos, trabalha-se com retornos crescentes de escala - com variações mais que proporcionais de produtos, e, em um cenário com muitos recursos, trabalha-se com retornos decrescentes de escala, ou seja, com variações proporcionalmente menores de produtos.

O presente estudo tem como DMUs países com características distintas entre si, seja em tamanho do espaço geográfico, seja no tamanho de suas próprias economias. Nesse sentido, pode-se dizer que o modelo VRS é a alternativa mais adequada quando se tem como objetivo comparar países de portes muito diferentes, de forma que as unidades (países) tenham como referências outras com características semelhantes.

Assim, na orientação produto, os insumos são fixos e o produto pode ser expandido, com pressuposição de retornos variáveis à escala, conforme apresentado na expressão 1 :

$$
\begin{aligned}
& \operatorname{Max}_{\varphi, \lambda} \phi \\
& \text { sujeito a: } \\
& -\mathrm{y}_{\mathrm{i}}+\mathrm{Y} \lambda \geq 0, \\
& \phi \mathrm{X}_{\mathrm{i}}-\mathrm{X} \lambda \geq 0, \\
& \mathrm{~N}_{1}{ }^{\prime} \lambda=1 \\
& \lambda \geq 0
\end{aligned}
$$

em que $\mathrm{y}_{\mathrm{i}}$ é um vetor ( $\left.m \times 1\right)$ de quantidades de produtos da i-ésima DMU; $\mathrm{x}_{\mathrm{i}}$ é um vetor ( $k$ x 1) de quantidades de insumos da i-ésima DMU; Y é a matriz ( $n \times m$ ) de produtos das $n$ DMUs; $X$ é uma matriz $(n \times k)$ de insumos das $n$ DMUs; $\lambda$ é um 
vetor ( $n \times 1)$ de pesos; $1 \leq \phi<\infty$ e $1 / \phi$ é a eficiência técnica que varia de zero a um; e $N_{1}$ é um vetor ( $\left.n \times 1\right)$ de números uns que introduz ao modelo a restrição de convexidade.

\section{2 Índice de Produtividade de Malmquist}

Os modelos clássicos de DEA (CCR e BCC) são análises estáticas de um conjunto de DMUs, ou seja, a estimativa da eficiência é realizada em um único corte temporal. Para se mensurar a evolução da eficiência ao longo de um período de tempo, é necessário utilizar-se uma abordagem que permita verificar a dinâmica das DMUs. Extensões dos modelos clássicos permitem considerar técnicas não paramétricas em DEA sob circunstâncias dinâmicas, entre elas destaca-se o IM.

O IM foi desenvolvido no estudo de Malmquist (1953), que visa à elaboração de um índice comparativo para a análise do consumo em razão de funções distância. O IM representa a evolução da produtividade total dos fatores (PTF) de uma DMU em consonância com as alterações da eficiência técnica e de mudanças tecnológicas entre períodos de tempo, admitindo múltiplos insumos e produtos (COOPER; SEIFORD; TONE, 2007). A PTF reflete a contribuição de todos os insumos produtivos na formação do produto, e, consequentemente, melhoras na PTF contribuem para um melhor desempenho da DMU.

O IM normalmente é utilizado em técnicas não paramétricas para a análise dinâmica da produtividade, como a DEA. Os trabalhos de Färe et al. $(1990,1991)$ são precursores no exame não paramétrico do IM orientado a produto, $I M_{o}$, que avalia as modificações da PTF caracterizada por uma tecnologia de produção que objetiva a maximização proporcional do vetor produto, entres os períodos $t$ e $t$ + 1. A representação algébrica do $I M_{o}$ sob orientação produto é apresentada na expressão 2 :

$$
I M_{o}=\left[\frac{D_{o}^{t}\left(x_{o}^{t+1} y_{0}^{t+1}\right)}{D_{o}^{t}\left(x_{o}^{t} y_{I}^{t}\right)} \frac{D_{O}^{t+1}\left(x_{o}^{t+1} y_{o}^{t+1}\right)}{D_{o}^{t+1}\left(x_{o}^{t} y_{o}^{t}\right)}\right]^{1 / 2}
$$

em que o índice é composto por quatro termos, sendo que dois correspondem aos períodos de tempo te $t+1, \mathrm{D}_{\mathrm{o}}^{\mathrm{t}}\left(\mathrm{x}_{\mathrm{o}}^{\mathrm{t}+1} \mathrm{y}_{\mathrm{o}}^{\mathrm{t}+1}\right)$ e $\mathrm{D}_{\mathrm{o}}^{\mathrm{t}+1}\left(\mathrm{x}_{\mathrm{o}}^{\mathrm{t}+1} \mathrm{y}_{\mathrm{o}}^{\mathrm{t}+1}\right)$, respectivamente, bem como $\mathrm{D}_{\mathrm{o}}{ }^{\mathrm{t}}\left(\mathrm{x}_{\mathrm{o}}^{\mathrm{t}} \mathrm{y}_{\mathrm{o}}^{\mathrm{t}}\right)$ e $\mathrm{D}_{\mathrm{o}}^{\mathrm{t}+1}\left(\mathrm{x}_{\mathrm{o}}^{\mathrm{t}} \mathrm{y}_{\mathrm{o}}^{\mathrm{t}}\right)$ referem-se à comparação intertemporal. $\mathrm{A}$ expressão 2 indica que: $\mathrm{se}^{\mathrm{IM}_{\mathrm{o}}}>1$, houve melhora na produtividade da $D M U_{i}$ ao longo do tempo; se $\mathrm{IM}_{\mathrm{o}}<1$, houve piora na produtividade da $D M U_{i}$ ao longo do tempo; e, se = 1 , a produtividade da $D M U_{i}$ manteve-se constante ao longo do tempo. O IM, IM , resulta do produto do emparelhamento pelo deslocamento da fronteira. Assim, o IM permite dividir a variação da PTF em dois efeitos: alterações 
na eficiência técnica (ET), ou catch-up (efeito emparelhamento), e modificações na tecnologia (T), ou frontier-shift effect (efeito deslocamento).

O primeiro efeito avalia o aumento ou a diminuição da eficiência técnica ao longo do tempo, ou seja, permite verificar as mudanças no processo produtivo de uma mesma tecnologia. O segundo efeito verifica as alterações na produtividade devido ao avanço tecnológico. Esses efeitos são apresentados, algebricamente, de acordo com as expressões 3 e 4, respectivamente:

$$
\begin{gathered}
E T=\frac{D_{o}^{t+1}\left(x_{o}^{t+1} y_{o}^{t+1}\right)}{D_{o}^{t}\left(x_{o}^{t} y_{o}^{t}\right)} \\
T=\left[\frac{D_{o}^{t}\left(x_{o}^{t} y_{o}^{t}\right)}{D_{o}^{t+1}\left(x_{o}^{t} y_{o}^{t}\right)} \frac{D_{o}^{t}\left(x_{o}^{t+1} y_{o}^{t+1}\right)}{D_{o}^{t+1}\left(x_{o}^{t+1} y_{o}^{t+1}\right)}\right]^{1 / 2}
\end{gathered}
$$

em que $\mathrm{D}_{\mathrm{o}}{ }^{\mathrm{t}}\left(\mathrm{x}_{\mathrm{o}}{ }^{\mathrm{t}} \mathrm{y}_{\mathrm{o}}^{\mathrm{t}}\right)$ é a eficiência técnica da $D M U_{-} k$ objetivo $(k=0)$ no período de tempo $t$; e $\mathrm{D}_{\mathrm{o}}{ }^{\mathrm{t}+1}\left(\mathrm{x}_{\mathrm{o}}{ }^{\mathrm{t}+1} \mathrm{y}_{\mathrm{o}}{ }^{\mathrm{t}+1}\right)$ é a eficiência técnica da $D M U_{-} k$ objetivo $(k=0)$ no período de tempo $t+1$. O emparelhamento $(E T>1)$ significa que a eficiência técnica entre os períodos $t$ e $t+1$ melhorou; $E T=1$ significa que a eficiência técnica permaneceu constante em $t$ e $t+1$, e $E<1$ significa que a eficiência técnica piorou entre os períodos $t$ e $t+1$. Assim, o efeito emparelhamento capta a mudança da distância que os fatores de produção observados estão em relação aos fatores de produção mínimos que ainda produzem outputs desejados e que estão sobre a fronteira eficiente no intervalo de tempo em análise.

Os avanços na produtividade podem ser observados a partir das inovações tecnológicas (frontier-shift effect). Desse modo, o aumento de produtividade pode resultar da introdução de tecnologias mais avançadas, ou seja, que produzem um produto melhor com menor utilização de insumos. A expressão 4 representa a utilização da DEA com orientação produto de forma genérica, com um insumo e um produto. O deslocamento da fronteira maior que $1(T>1)$ significa progresso tecnológico no período $t+1$, em relação ao período $t$; se $T=1$, não houve mudança tecnológica, e se $T<1$, indica regresso tecnológico.

\subsection{Análise de Convergência via Cadeia de Markov}

Uma cadeia de Markov é um caso particular de processo estocástico em que a ocorrência de um estado futuro depende apenas do estado imediatamente anterior. Isto é, dado um período de tempo $t_{0}, t_{1}, \ldots, t_{n}$, diz-se que a sucessão de variáveis aleatórias $\left\{X_{t n}\right\}=\left\{x_{1}, x_{2}, \ldots, x_{n}\right\}$ é um processo ou uma cadeia de Markov se respeitar a seguinte propriedade (TAHA, 2008): 


$$
P\left\{X_{t_{n}}=x_{n} \mid X_{t_{n-1}}=x_{n-1}, \ldots, X_{t_{0}}=x_{0}\right\}=P\left\{X_{t_{n}}=x_{n} \mid X_{t_{n-1}}=x_{n-1}\right\}
$$

Em uma cadeia de Markov com $n$ estados (resultados, classes ou estratos), as probabilidades em um ponto específico do tempo $t=0,1,2, \ldots$ são expressas conforme a expressão 6:

$$
p_{i j}=P\left\{X_{t}=j \mid X_{t-1}=i\right\},(i, j)=1,2, \ldots, n, t=0,1,2, \ldots, T
$$

$p_{i j}$ é a probabilidade de transição do estado $i$, em $t$ - 1, para o estado j em $t$. Por definição:

$$
\begin{gathered}
\sum_{j} p_{i j}=1, i=1,2, \ldots n \\
p_{i j} \geq 0,(i, j)=1,2, \ldots, n
\end{gathered}
$$

As probabilidades de transição de um estado para outro podem ser mostradas como uma matriz quadrada $P=\left[p_{i j}\right]$ designada como matriz de transição da cadeia de Markov, conforme a expressão 7:

$$
P=\left\{\begin{array}{ccccc}
p_{1} & p_{\mathrm{R}} & p_{\mathrm{B}} & \cdots & p_{1 n} \\
p_{1} & p_{2} & p_{3} & \cdots & p_{2 n} \\
\vdots & \vdots & \vdots & \vdots & \vdots \\
p_{n 1} & p_{n 2} & p_{n 3} & \cdots & p_{n}
\end{array}\right\}
$$

A matriz $P$ define genericamente a cadeia de Markov e tem como propriedade que todas as probabilidades de transição $\left(p_{i j}\right)^{1}$ presentes na matriz sejam estacionárias e independentes ao longo do tempo (TAHA, 2008). Isto é, as probabilidades não modificam em relação ao tempo, mas de um estado para outro. Essas características são fundamentais para a análise de convergência, uma vez que esta pressupõe que as séries sejam estacionárias.

A estacionariedade das probabilidades permite que a matriz de transição possa ser utilizada para descrever o comportamento da eficiência para qualquer horizonte de tempo, o que possibilita avaliar a dinâmica de longo prazo das classes de eficiência e o equilíbrio no estado estacionário (QUAH, 1993). Em uma cadeia

$1 \quad$ No contexto deste trabalho, $p_{i j}$ é entendia como a probabilidade de transição de um país que estava em um estado (classe ou estrato) de eficiência $i$, em 2000, para o estado j em 2010. 
de Markov ergódica, as probabilidades de estado no equilíbrio $\left(\pi_{\mathrm{j}}\right)$ são determinadas pela expressão 8:

$$
\pi_{j}=\lim _{n \rightarrow \infty} a_{j}^{(n)}, j=0,1,2, \ldots
$$

em que $a_{j}^{(n)}$ são as probabilidades absolutas de estar no estado j após $n$ transições $(\operatorname{com} n>0){ }^{2}$ Essas probabilidades são independentes das probabilidades iniciais $\left\{a_{j}^{(0)}\right\}$, e, portanto, a classificação da eficiência deve convergir para uma classificação estacionária. Essas probabilidades são definidas com base na expressão 9:

$$
\begin{aligned}
& \pi=\pi P \\
& \sum_{j} \pi_{j}=1
\end{aligned}
$$

Como observa Taha (2008), a expressão 9 mostra que se as probabilidades $\pi$ permanecerem inalteradas depois de uma transição, representam a distribuição do estado no equilíbrio (estado estacionário). Outro resultado direto das probabilidades no estado estacionário é o número esperado de transições antes dos sistemas retornarem para um estado j pela primeira vez. Esse resultado é denominado como tempo médio do primeiro retorno ou tempo médio de recorrência, $\mu_{i j}$, e é estimado em uma cadeia de Markov de $n$ estados, conforme a expressão 10:

$$
\mu_{\ddot{j}}=\frac{1}{\pi_{j}}, j=1,2, \ldots, n
$$

\subsection{Fonte e Tratamento dos Dados}

A metodologia de DEA se mostra sensível à definição das variáveis que representarão os insumos e os produtos para gerarem um ranking de eficiências. Para que não fossem escolhidas de maneira aleatória, o que poderia vir a gerar viés nos resultados, optou-se por selecionar variáveis utilizadas em outros estudos que também abordaram o progresso da ciência e da tecnologia. Com isso, fez-se uso das mesmas variáveis utilizadas por Ribeiro et al. (2006a, 2006b), Herskovic, Ribeiro e Albuquerque (2008) e Alves, Toyoshima e Torres (2014).

Para se representar os insumos (inputs) dos modelos a serem utilizados, fez-se uso das variáveis: pesquisadores em PEBD (por milhão de habitantes) e gastos com

2 Isso é o mesmo que multiplicar a matriz de transição $(P)$ por ela mesma n vezes e observar se a matriz converge para valores constantes. 
pesquisa e desenvolvimento (por milhão de habitantes), fornecidos pelo Banco Mundial (WORLD BANK, 2010).

Para se representar os produtos (outputs), utilizou-se a média anual do número de artigos publicados em revistas internacionais por milhão de habitantes - fornecido pelo Institute of Scientific Information (ISI) -, como forma de representar o desenvolvimento científico, e a média anual do número de patentes por milhão de habitantes - concedido pelo United States Patent and Trade Office (USPTO) - para representar o progresso tecnológico (UNITED STATES OF AMERICA, 2012).

Os dados coletados para o presente trabalho foram referentes a todos os países para os anos de 2000, 2005 e 2010. Porém, salienta-se que, diante da sensibilidade dos métodos de DEA quanto a valores faltantes para alguma DMU (países), foi necessária a exclusão de alguns países. Portanto, têm-se uma base de dados com 53 países que contém as informações descritas para os anos de 2000, 2005 e 2010. Salienta-se também que o ano de 2005 apenas será utilizado para verificar a evolução da produtividade no IM.

No Quadro 1 são apresentados os 53 países (DMUs) objetos de análise no presente trabalho.

Quadro 1 - Países utilizados para quantificar a eficiência em gerar progresso científico e tecnológico (2000, 2005 e 2010)

\begin{tabular}{|l|l|l|l|}
\hline \multicolumn{5}{|c|}{ Países } \\
\hline África do Sul & Croácia & Índia & Nova Zelândia \\
\hline Alemanha & Dinamarca & Irlanda & Panamá \\
\hline Argentina & Eslováquia & Islândia & Polônia \\
\hline Austrália & Eslovênia & Itália & Portugal \\
\hline Áustria & Espanha & Japão & Reino Unido \\
\hline Bélgica & Estônia & Kuwait & República Tcheca \\
\hline Brasil & Estados Unidos & Letônia & Romênia \\
\hline Bulgária & Finlândia & Lituânia & Rússia \\
\hline Canadá & França & Luxemburgo & Singapura \\
\hline China & Grécia & Macedônia & Sri Lanka \\
\hline Chipre & Holanda & Malásia & Suécia \\
\hline Colômbia & Hong Kong & México & Tailândia \\
\hline Coreia & Hungria & Noruega & Tunísia \\
\hline & & & Turquia \\
\hline
\end{tabular}

Fonte: Elaboração própria a partir de resultados da pesquisa. 


\section{Resultados e Discussão}

\subsection{Análise da Eficiência da Orientação Produto com Retornos Variáveis de Escala}

A distribuição das frequências absolutas e relativas do progresso científico e tecnológico dos países no ano 2000 e 2010, segundo intervalos de medidas de eficiência técnica, sob a orientação produto e retornos variáveis de escala, pode ser observada na Tabela 1. De posse desses resultados, constata-se que, dos 53 países analisados para o ano de 2000, a maior predominância de países avaliados encontra-se na classe D de eficiência ( $0,00 \%$ - 39,99\%), já que cerca de $45 \%$ dos países estão concentrados nesse intervalo. A definição desses quatro grupos foi feita visto que, a partir da subdivisão em cinco grupos ou mais, alguns grupos passaram a não possuir países existentes, ou seja, alguns grupos ficaram vazios. Portanto, a escolha de apenas quatro grupos foi tomada para que em cada grupo de eficiência existisse pelo menos um país e este pudesse migrar de grupo ao analisar a evolução da eficiência ao longo do tempo, condição fundamental para alimentar a cadeia de Markov.

Tabela 1 - Distribuição de frequências absolutas e relativas observadas para as diferentes classes de eficiência com retornos variáveis de escala (2000 e 2010)

\begin{tabular}{|c|c|c|c|c|c|}
\hline Classe & Amplitude & $\begin{array}{c}\text { Frequência } \\
\text { absoluta } \\
2000\end{array}$ & $\begin{array}{c}\text { Frequência } \\
\text { relativa } \\
2000\end{array}$ & $\begin{array}{c}\text { Frequência } \\
\text { absoluta } \\
2010\end{array}$ & $\begin{array}{l}\text { Frequência } \\
\text { relativa } \\
2010\end{array}$ \\
\hline \multirow[b]{2}{*}{$\mathbf{A}$} & $100,00 \%$ & 8 & $15,09 \%$ & 16 & $30,18 \%$ \\
\hline & $\begin{array}{c}90,00 \%- \\
99,99 \%\end{array}$ & 1 & $1,88 \%$ & 6 & $11,32 \%$ \\
\hline B & $\begin{array}{c}70,00 \% \text { - } \\
89,99 \%\end{array}$ & 9 & $16,98 \%$ & 12 & $22,64 \%$ \\
\hline C & $\begin{array}{c}40,00 \% \text { - } \\
69,99 \%\end{array}$ & 11 & $20,75 \%$ & 14 & $26,41 \%$ \\
\hline D & $\begin{array}{l}0,00 \%- \\
39,99 \%\end{array}$ & 24 & $45,28 \%$ & 5 & $9,43 \%$ \\
\hline Total & & 53 & $100,00 \%$ & 53 & $100,00 \%$ \\
\hline Mínimo & & 0,06 & & 0,25 & \\
\hline Média & & 0,53 & & 0,77 & \\
\hline Máximo & & 1,00 & & 1,00 & \\
\hline $\begin{array}{l}\text { Desvio } \\
\text { padrão }\end{array}$ & & 0,31 & & 0,23 & \\
\hline
\end{tabular}

Fonte: Elaboração própria a partir de resultados da pesquisa. 
No que se refere à máxima eficiência do ano 2000, cerca de 15\%, que corresponde a 8 do total de 53 países, obtiveram 100\% de eficiência. Assim, apenas Estados Unidos, Suécia, Sri Lanka, Panamá, Kuwait, Hong Kong, Colômbia e Austrália obtiveram eficiência máxima e encontram-se na fronteira de possibilidade de produção.

Já para o ano de 2010 nota-se que a maioria dos países estudados, ou seja, 30,18\%, obteve $100 \%$ de eficiência e está na classe mais alta (classe A). Os 16 países que obtiveram máxima eficiência no ano de 2010 são: Estados Unidos, Bulgária, Canadá, Croácia, Kuwait, Chipre, Finlândia, Macedônia, Islândia, Holanda, Nova Zelândia, Panamá, Romênia, Sri Lanka, Singapura e Suécia, assim encontram-se na fronteira de possibilidade de produção com retornos variáveis. Nota-se ainda que a amplitude dos valores de eficiência varia entre $25 \%$ (menos eficientes) e 100\% (mais eficientes) em 2010.

Apesar de alguns países serem menos desenvolvidos, podem ser tecnicamente eficientes em produzir artigos e patentes, dados os seus insumos, tanto quanto países mais desenvolvidos. Esses países estão fazendo o melhor que podem, apesar de possuírem recursos mais limitados, e isso tem impacto direto nos níveis de eficiência técnica. Ao se mensurar se determinado país consegue produzir de maneira tecnicamente eficiente, não quer dizer que ele estará produzindo artigos e patentes em larga escala, mas sim que estará alocando seus pesquisadores e seus recursos disponíveis para pesquisa da melhor maneira possível, sem que precise modificar qualquer fator de produção (insumos e/ou produtos).

\subsection{Análise do Índice de Malmquist e seus Componentes}

O sistema de interação das empresas privadas e públicas (grandes ou pequenas), universidades e agências governamentais, com vistas à produção de ciência e tecnologia dentro das fronteiras nacionais, pode ser de natureza técnica, comercial, jurídica, social e financeira. O objetivo da interação é o desenvolvimento, proteção, financiamento ou regulamentação da nova ciência e tecnologia. Mais especificamente, deve-se assumir a liderança no apoio a áreas específicas da nova investigação genérica, para dar às empresas e outros atores a confiança de que as capacidades locais estarão disponíveis para contribuir para o desenvolvimento dos SNI (NIOSI et al., 1993; ANTONELLI, 2005).

Dada a importância da diversificação das fontes de crescimento econômico, busca-se identificar os papéis respectivos de acumulação de fatores e da PTF como fontes de crescimento de dada economia. Além disso, busca-se compreender o crescimento da PTF e decompô-la em mudança na eficiência técnica e mudança tecnológica através do IM. 
Pode-se notar, por meio da Tabela 2, que o período de 2000 a 2005 apresentou uma representativa mudança na eficiência técnica, em média, de $85 \%$. Porém, mostrou o pior desempenho com retrocesso tecnológico de 37,3\%. Contudo, a PTF aumentou 16,5\%. No período de 2005 a 2010, pode-se observar uma piora na eficiência técnica (retrocesso de cerca de $2 \%$ ). Observa-se, ainda, que houve progresso tecnológico de 49\%, além de uma melhora na PTF em 47,3\%. Já quando o período é analisado como um todo (2000 a 2010), houve melhora na eficiência técnica de $83 \%$, apesar do retrocesso tecnológico de $12 \%$, porém a produtividade aumentou em 61\% nos 11 anos analisados.

Tabela 2 - Decomposição do IM segundo progresso tecnológico dos países (2000-2010)

\begin{tabular}{c|lc}
\hline Ano & \multicolumn{1}{|c}{ Variável } & Média \\
\hline \multirow{2}{*}{$2000-$} & Mudança na eficiência técnica & 1,856 \\
2005 & Mudança tecnológica & 0,627 \\
& Mudança na PTF & 1,165 \\
\hline \multirow{2}{*}{$2005-$} & Mudança na eficiência técnica & 0,986 \\
2010 & Mudança tecnológica & 1,494 \\
& Mudança na PTF & 1,473 \\
\hline \multirow{2}{*}{$2000-$} & Mudança na eficiência técnica & 1,831 \\
2010 & Mudança tecnológica & 0,880 \\
& Mudança na PTF & 1,611 \\
\hline
\end{tabular}

Fonte: Elaboração própria a partir de resultados da pesquisa.

Ao se analisar o IM para os 53 países em estudo, nos anos de 2000-2010 observa-se que $83 \%$ dos países apresentaram aumento de produtividade, ou seja, apresentaram IM maior que um, dos quais podemos elencar os 10 melhores índices no período para Romênia, Croácia, Tailândia, Macedônia, Lituânia, Grécia, Panamá, Bulgária, Índia e Brasil. Observa-se que nove países diminuíram a produtividade (Luxemburgo, Itália, Kuwait, Rússia, Estônia, Áustria, Hong Kong, Japão e Suécia), pois obtiveram os piores índices para o período como um todo (2000 a 2010).

Pode-se notar que a Suécia e o Kuwait obtiveram eficiência de $100 \%$ nos anos de 2000 e 2010, comparativamente aos demais países em estudo. Porém, apresentaram queda de produtividade ao longo desse período. Essa perda de produtividade não foi suficiente para que esses países saíssem da fronteira de possibilidade de produção, porém, se houver repetições seguidas dessa diminuição na PTF ao longo do tempo, poderá levar esses países a se deslocarem da fronteira eficiente.

No período de 2000 a 2005, apenas $43 \%$ dos países apresentaram aumentos na PTF, com destaque para Romênia, Macedônia, Grécia, Eslováquia, Polônia, 
Portugal, Brasil, Panamá e Índia. Observa-se, ainda, que 23 países reduziram a produtividade, dos quais pode-se destacar alguns como Kuwait, Sri Lanka, Hungria, Hong Kong e Canadá, que obtiveram os piores índices para o período analisado.

Para o período de 2005 a 2010, cerca de $92 \%$ dos países apresentaram aumentos na PTF, ou seja, apresentaram IM superior que um, com destaque para Sri Lanka, Croácia, Lituânia, Kuwait, Tailândia, Romênia, Tunísia e Bulgária. Cabe salientar que apenas quatro países diminuíram a produtividade (Eslováquia, Portugal, Letônia e Estônia), pois obtiveram os piores índices para o período de 2005 a 2010.

O efeito emparelhamento (mudança na eficiência técnica) mostrou-se mais relevante nos períodos de 2000 a 2005 e 2000 a 2010, ou seja, verificou-se que houve mudanças significativas no processo produtivo de uma mesma tecnologia. Os países se tornaram, em média, mais eficientes mantendo a forma de produzir novos produtos científicos (artigos) e tecnológicos (patentes).

Já para o período de 2005 a 2010, a mudança tecnológica foi o fator que mais impactou o IM dos países analisados, mostrando que obtiveram, em média, melhoras de produtividade devido às mudanças na tecnologia, apesar da piora da eficiência técnica. Após elevações na eficiência para a produção de novos artigos e criação de novas patentes no período que compreendeu 2000 a 2005, houve a necessidade de uma mudança no formato do processo de operacionalização (mudança tecnológica) a fim de acompanhar todo o processo de crescimento da eficiência que vinha até então acontecendo. Com isso, o período subsequente (2005 a 2010), veio acompanhado de mudanças significativas na tecnologia, bem como de um dado retrocesso na eficiência dos países, sendo necessário um período de adaptação desses novos métodos para geração de novos produtos para que houvesse novamente retorno da eficiência técnica.

Ao romper um paradigma tecnológico (mudança da tecnologia), os países necessitam de um período para adaptação da nova tecnologia. Assim, durante esse período, provavelmente haverá perda de eficiência. Porém, ao se adaptarem ao novo processo adotado, os países retornarão aos níveis de eficiência e ganhos de produtividade à medida que se adéquem aos novos métodos na geração de produtos.

\subsection{Análise da Convergência da Eficiência}

Para a análise da convergência da eficiência foi utilizada uma cadeia de Markov discreta, finita e de primeira ordem, isto é, foi analisada a transição da eficiência técnica entre dois períodos, 2000 e 2010, com um número finito de classes de eficiência. Segundo Pôrto Júnior e Ribeiro (2003), não existe uma regra única para estabelecer a amplitude das classes, apenas critérios arbitrários. Dessa forma, 
a eficiência técnica foi dividida em quatro classes, sendo a classe A a mais eficiente (90\% a 100\%) e a D (0\% a 39,99\%) a menos eficiente. A Tabela 1 (ver seção 4.1) ilustra com mais propriedade as classes determinadas neste estudo, suas amplitudes e as respectivas frequências absolutas e relativas para os anos de 2000 e 2010. Os resultados observados para as frequências relativas servem de base para a construção da matriz de transição utilizada na cadeia de Markov, conforme a Tabela 3 mostra:

Tabela 3 - Matriz de transição de Markov para as diferentes classes de eficiência (2000 e 2010)

\begin{tabular}{llcccc}
\hline & & \multicolumn{4}{c}{ Classe no periodo posterior (2010) } \\
\cline { 3 - 6 } & & A & B & C & D \\
Classe no perio- & A & 0,7778 & 0,2222 & 0,0000 & 0,0000 \\
do inicial (2000) & B & 0,5556 & 0,3333 & 0,1111 & 0,0000 \\
& C & 0,4550 & 0,2730 & 0,2720 & 0,0000 \\
& D & 0,2083 & 0,1667 & 0,4167 & 0,2083 \\
\hline
\end{tabular}

Fonte: Elaboração própria a partir de resultados da pesquisa.

De acordo com Anderson e Goodman (1957), Bickenbach e Bode (2001, 2003) 3 e Mossi et al. (2003), testes de qui-quadrado e likelihood ratio (LR) devem ser aplicados na matriz de transição para verificar se as probabilidades nela contidas são constantes e independentes ao longo do tempo e do espaço. Ou seja, esses testes indicam se as probabilidades de transição são homogêneas no tempo e entre as regiões (clusters) e se seguem um processo markoviano.

Tais testes visam comparar as probabilidades contidas na matriz de transição de toda a amostra com as probabilidades contidas em subamostras, que são construídas a partir da subdivisão de todo o período em diversas partes de tempo e regiões. Para que os testes de qui-quadrado e LR sejam aplicados, é necessário que o número de observações seja amplo. Caso contrário, a estimativa será incerta e não confiável.

O número de observações utilizadas nesse trabalho é de 106 (53 países e 2 anos), o que gera um painel com poucas observações e, com isso, inviabiliza a aplicação dos testes citados. De posse de apenas dois anos de análise, consegue-se gerar apenas uma matriz de transição, sem que seja possível subdividir esse período em mais períodos e retirar outras submatrizes. A redução do número de observações foi devida à aplicação da metodologia DEA, anteriormente utilizada para quantificar as eficiências científico-tecnológicas. Por ser uma metodologia

3 Para mais detalhes sobre as estatísticas dos testes, ver Anderson e Goodman (1957), Bickenbach e Bode (2001, 2003) e Mossi et al. (2003). 
comparativa, a DEA não admite dados faltantes, seja ao longo do tempo ou de regiões, e, por isso, muitos países e anos tiveram que ser retirados da amostra inicial.

Porém, parte da literatura ${ }^{4}$ assume que as probabilidades contidas na matriz de transição seguem um processo markoviano estocástico por definição, com características estacionárias e independentes ao longo do tempo. Nesse sentido, a matriz de transição apresentada na Tabela 3 consiste em uma matriz de probabilidades, que revela a probabilidade de transição dos países em estudo, entre as quatro classes de eficiência no ano de 2000 para 2010.Observa-se na matriz que não há estados absorventes, isto é, não existe certeza, em nenhuma das classes, de permanência da classe de eficiência inicial para o período seguinte $\left(p_{i j}\right.$ $\neq 1$ ). Por exemplo, a maior probabilidade de permanência é verificada na linha A coluna A, ou seja, do total de países que estavam na classe mais elevada de eficiência (classe A) em 2000, 77,78\% permaneceram em A, 22,22\% migraram para classe B e nenhum país migrou para as classes de eficiência inferiores (C e D). Pode-se inferir, ainda, que, por a classe A apresentar a menor mudança relativa de um ano para o outro, existe certa estabilidade dos níveis de eficiência dos países que a compõem. Dessa forma, é provável que esses países sejam tomados como referência (benchmark) das melhores práticas produtivas, tanto no curto quanto no longo prazo.

Por outro lado, 33,3\% dos países que estavam na classe B em 2000 permaneceram nela em 2010, 55,5\% evoluíram para a classe de eficiência superior e 11,1\% migraram para a classe inferior $\mathrm{C}$. Na classe de eficiência $\mathrm{D}$, a mais baixa, com eficiência inferior a 40\%, 20,8\% dos países permaneceram nela, 41,6\% migraram para a classe C, 16,6\% migraram para a classe B e 20,8\% evoluíram para a classe mais alta A. De modo geral, a maior parte dos países permaneceu ou evoluiu de classes de um ano para o outro, o que demonstra tendência de evolução positiva da eficiência técnica no longo prazo.

Essa hipótese pode ser demonstrada empiricamente por meio da cadeia de Markov a partir da solução das expressões 9 e 10 expostas na seção 3.3. Essas soluções são apresentadas na Tabela 4 e na Figura 1. Nelas, encontram-se os valores da distribuição inicial dos países entre as diferentes classes, a solução das expressões para $n=1,3,5,7$ e 10 períodos à frente, as probabilidades de equilíbrio de longo prazo (estado estacionário) por classes de eficiência e o tempo médio de recorrência. 
Tabela 4 - Distribuição de frequências observadas e estimadas para diferentes transições

\begin{tabular}{|c|c|c|c|c|c|c|c|c|}
\hline \multirow[b]{2}{*}{ Classe } & \multirow{2}{*}{$\begin{array}{r}\text { Distri- } \\
\text { buição } \\
\text { inicial } \\
(2000) \\
\end{array}$} & \multicolumn{5}{|c|}{ Número de transições } & \multirow{2}{*}{$\begin{array}{c}\text { Estado } \\
\text { estacionário } \\
(\pi)\end{array}$} & \multirow{2}{*}{$\begin{array}{c}\text { Tempo } \\
\text { médio de } \\
\text { recorrên- } \\
\text { cia }(\mu)\end{array}$} \\
\hline & & $\mathbf{1}$ & 3 & 5 & 7 & 10 & & \\
\hline $\mathbf{A}$ & 0,1698 & 0,4152 & 0,7093 & 0,7046 & 0,7088 & 0,7093 & 0,70934 & 1,4097 \\
\hline B & 0,1698 & 0,2265 & 0,2564 & 0,2529 & 0,2522 & 0,2521 & 0,25217 & 3,9655 \\
\hline $\mathbf{C}$ & 0,2080 & 0,2639 & 0,0736 & 0,0422 & 0,0388 & 0,0384 & 0,03848 & 25,984 \\
\hline D & 0,4524 & 0,0942 & 0,0041 & 0,00018 & $7,7 \mathrm{E}-6$ & $7,0 \mathrm{E}-8$ & 0,00000 & Infinito \\
\hline
\end{tabular}

Fonte: Elaboração própria a partir de resultados da pesquisa.

Figura 1 - Trajetórias e tempo de convergência para o estado estacionário

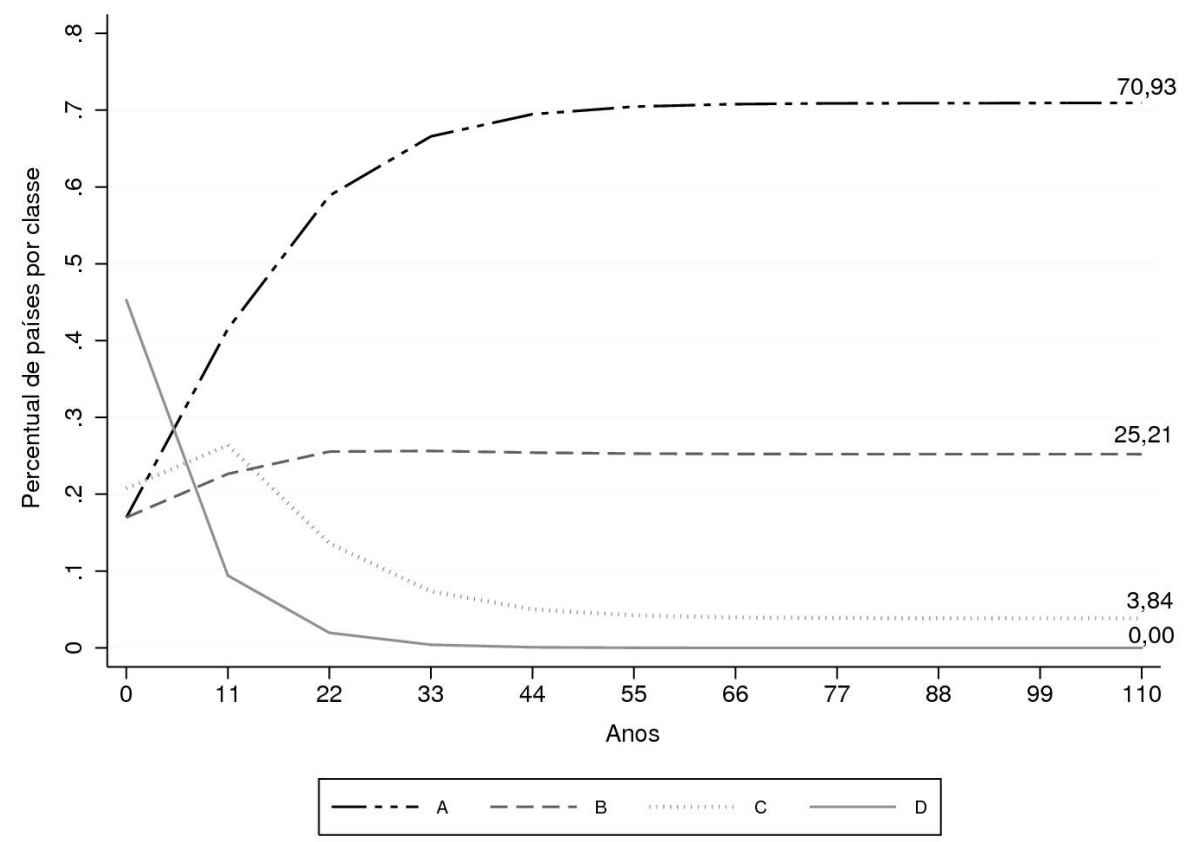

Fonte: Elaboração própria a partir dos dados da pesquisa.

É nítida, tanto na Tabela 4 quanto na Figura 1, a evolução significativa da classe A, a classe com maior nível de eficiência técnica. Em 2000, 16,98\% dos países pertenciam a essa classe, por outro lado, no estado estacionário existe uma probabilidade de 70,93\% dos países estarem nessa classe de eficiência no longo prazo. A classe B também teve incremento na probabilidade de longo prazo, enquanto que as classes $\mathrm{C}$ e $\mathrm{D}$ perderam participação nos níveis de probabilidade. 
Em 2000, havia probabilidade de 66,04\% dos países estarem em alguma dessas classes (C e D), no entanto, no equilíbrio de longo de prazo (estado estacionário), essa probabilidade reduziu para menos de $4 \%$.

A redução da discrepância da produtividade entre os países é um fator que pode contribuir para o processo de convergência. É importante que os países promovam uma verdadeira transformação estrutural, expandido setores mais produtivos e retraindo os menos e, ao mesmo tempo, desenvolvendo capacidades fundamentais na forma de capital e instituições humanas (RODRIK, 2013). Como pode ser observado na Tabela 2, é nítida a elevação média da PTF entre 2000 e 2010 (61\%). Reduzir as disparidades pode contribuir para o aumento da probabilidade de equilíbrio de longo prazo observada na classe A da Tabela 4, contribuindo para o processo de convergência para um padrão de eficiência elevado.

A Tabela 4 e a Figura 1 também revelam que, embora exista uma probabilidade de cerca de $70 \%$ dos países estarem na classe mais elevada de eficiência (classe A) no estado estacionário, o tempo para que isso ocorra gira em torno de 10 períodos, o que equivale a 110 anos (11 x 10). Além disso, mesmo que os países saiam da classe A, o tempo médio de recorrência $(\mu)$ de retornar a ela é de 1,409 períodos, ou aproximadamente 15 anos (11 x 1,409).

\section{Considerações Finais}

O nível de produtividade de uma economia pode ser entendido como a maneira com que os insumos são combinados na produção. Dessa forma, para uma quantidade de insumos, um aumento de produtividade pode se dar por meio de progresso tecnológico e/ou aumento da eficiência.

Ao se pensar o que levaria uma economia a produzir abaixo da fronteira tecnológica, ou seja, de maneira ineficiente, pode-se supor que uma das possíveis explicações seria a falta de infraestrutura adequada para se pesquisar e inovar. Como, em geral, o progresso científico e inovativo possui externalidades positivas associadas a um elevado retorno social, a subprovisão de investimento e acesso a uma infraestrutura mínima pode comprometer seriamente a produtividade dos países em inovação.

Pôde-se perceber que não necessariamente os países mais desenvolvidos serão os mais eficientes e produtivos em gerar níveis maiores de progresso científico e tecnológico. Países como Panamá, Kuwait, Sri Lanka e Colômbia, considerados como não desenvolvidos, foram elencados como eficientes para o ano 2000, conjuntamente com países mais ricos, como Estados Unidos, Suécia e Austrália, enquanto que, para o ano de 2010, Chipre e novamente Sri Lanka, Panamá e Kuwait foram tecnicamente eficientes. Pode-se perceber também que, no período de 2000 a 2010, alguns países como Panamá, Índia e Brasil estiveram entre as 10 
economias mais produtivas em gerar progresso científico e tecnológico, enquanto que Luxemburgo, Itália, Japão e Suécia tiveram queda de produtividade nesse mesmo período.

Esta conclusão resulta dos experimentos feitos através da aplicação dos métodos de DEA, e que, portanto, dão um indicativo de que não necessariamente os países precisam ser desenvolvidos para alocarem de maneira eficiente os seus recursos. Países menos desenvolvidos, que a princípio enfrentam barreiras socioeconômicas mais restritivas, também conseguem ajustar os seus insumos para níveis de produção tecnicamente eficientes. Os resultados não indicam que países em desenvolvimento produzirão progresso científico e tecnológico na mesma magnitude que países com alto grau de desenvolvimento, mas sim que os países menos desenvolvidos podem ser tão eficientes tecnicamente quanto os mais desenvolvidos. Apesar de alguns países com menos pesquisadores e com limitação de recursos disponíveis para pesquisa não gerarem progresso científico e tecnológico em larga escala, alguns deles conseguem gerar produtos de maneira eficiente de acordo com a quantidade de insumos que têm disponíveis.

No estado estacionário (equilíbrio de longo prazo), pôde-se notar que há probabilidade de mais da metade dos países convergir para a classe mais eficiente em gerar progresso científico e tecnológico. Mesmo atingindo o estado estacionário, faz-se necessária a manutenção do suporte das instituições de fomento à pesquisa, incentivos fiscais e subsídios à PEBD. A partir das externalidades geradas pelo conhecimento, os países adaptarão suas tecnologias de modo a alavancarem a produção de inovação de forma eficiente, o que possivelmente trará mudanças tecnológicas mais frequentes que sejam capazes de acompanhar a evolução da eficiência.

\section{Referências}

ALBUQUERQUE, E. M. Apresentação. Revista Brasileira de Inovação, Campinas, v. 3, n. 1, p. 9-13, jan./jun. 2004.

ALVES, F. F.; TOYOSHIMA, S. H.; TORRES, D. A. R. Fluxos desiguais do sistema financeiro e inovativo: uma análise das assimetrias entre países ricos e pobres. Análise Econômica, Porto Alegre, v. 32, n. 62, p. 63-84, 2014.

ANDERSON, T. W.; GOODMAN, L. A. Statistical inference about Markov chains. The Annals of Mathematical Statistics, Ann Arbor, Michigan, USA, v. 28, n.1, p. 89-110, Mar. 1957.

ANTONELLI, C. The governance of localized knowledge: an information economics approach for the economics of knowledge. Torino: Università di Torino, 2005. (Working paper $n^{\circ}$ 02/2005). 
BANKER, R. D.; CHARNES, H.; COOPER, W. W. Some models for estimating technical and scale inefficiencies in data envelopment analysis. Management Science, v. 30, n. 9, p. 10781092, 1984.

BICKENBACH, F.; BODE, E. Evaluating the Markov property in studies of economic convergence. International Regional Science Review, v. 26, n. 3, p. 363-392, 2003.

. Markov or not Markov: this should be a question. Kiel: Institut für Weltwirtschaft, 2001. (Kiel working paper $\mathrm{n}^{\circ}$ 1086).

CARVALHO, L.; AVELLAR, A. P. Inovação e produtividade: evidências empíricas para empresas brasileiras. In: ENCONTRO NACIONAL DE ECONOMIA, 41., 2013, Foz do Iguaçu. Anais... Niterói: Anpec, 2014.

COELLI, T. J. et al. An introduction to efficiency and productivity analysis. 2. ed. New York: Springer US, 2005.

COOPER, W.W.; SEIFORD, L. M.; TONE, K. Data envelopment analysis: a comprehensive text with models, applications, references and DEA-solver software. 2 ed. New York: Springer, 2007.

DIAZ-BALTEIRO, L. et al. An analysis of productive efficiency and innovation activity using DEA: an application to Spain's wood-based industry. Forest Policy and Economics, v. 8, n. 7, p. 762-773, 2006.

FÄRE, R. et al. Productivity growth in Illinois electric utilities. Resources and Energy, v. 12, n. 4, p. 383-398, Dec. 1990.

FÄRE, R. et al. Productivity in Swedish pharmacies: a Malmquist input index approach. Journal of Productivity Analysis, Boston, v. 3, n. 1/2, p. 270-285, 1991.

FERREIRA, C. M. C.; GOMES, A. P. Introdução à análise envoltória de dados: teoria, modelos e aplicações. Viçosa: UFV, 2009.

FREEMAN, C. Changes in the national system of innovation. Paris: OECD, 1987. (OECD working paper, [s. n.]).

. The "national system of innovation" in historical perspective. Cambridge Journal of Economics, London, v. 19, n. 1, p. 5-24, Feb. 1995.

GORDON, J. L. P. L. Sistema nacional de inovação: uma alternativa de desenvolvimento para os países da América Latina. In: ENCONTRO NACIONAL DE ECONOMIA POLÍTICA, 14., 2009, São Paulo. Anais... Niterói: SEP, 2009.

GUAN, J. C. et al. A study of the relationship between competitiveness and technological innovation capability based on DEA models. European Journal of Operational Research, v. 170, n. 3, p. 971-986, May 2006.

HASHIMOTO, A.; HANEDA, S. Measuring the change in RED efficiency of the Japanese pharmaceutical industry. Research Policy, v. 37, n. 10, p. 1829-1836, 2008. 
HERSKOVIC, B.; RIBEIRO, L. C.; ALBUQUERQUE, E. M. Efeitos recíprocos entre finanças e inovação. Belo Horizonte: Cedeplar/UFMG, 2008. (Texto para discussão $n^{\circ} 332$, maio 2008).

KRUEGER, D. Macroeconomic theory. [S. 1.], 2002. Disponível em: < http://www.ssc.wisc. edu/ asesh adr/econ714/MacroTheory.pdf> . Acesso em: 4 de maio 2015.

KRUSELL, P. Lecture notes for macroeconomics I. [S. 1.], 2004. Disponível em: < http://www. econ.yale.edu/smith/econ510a/book.pdf> . Acesso em: 4 de maior 2015.

LJUNGQVIST, L.; SARGENT, T. J. Recursive macroeconomic theory. 2. ed. Cambridge, MA, USA: MIT Press, 2000.

LOBO, M. S. C.; LINS, M. P. E. Avaliação da eficiência dos serviços de saúde por meio da análise envoltória de dados. Cadernos Saúde Coletiva, Rio de Janeiro, v. 19, n. 1, p. 93-102, 2011.

LUNDVALL, A-B. (Ed.). National systems of innovation: towards a theory of innovation and interactive learning. London: Pinter, 1992.

MALMQUIST, S. Index numbers and indifference curves. Trabajos de Estadística y de Investigación Operativa, v. 4, n. 1, p. 209-242, 1953.

MOSSI, M. B. et al. Growth dynamics and space in Brazil. International regional science review, v. 26, n. 3, p. 393-418, July 2003.

NELSON, R. (Ed.). National innovation systems: a comparative analysis. New York: Oxford University, 1993.

NIOSI, J. et al. Sistemas nacionais de inovação: em busca de um conceito viável. Tecnologia na Sociedade, v. 15, n. 2, p. 207-227, 1993.

PAN, T. W.; HUNG, S. W.; LU, W. M. DEA performance measurement of the national innovation system in Asia and Europe. Asia-Pacific Journal of Operational Research, v. 27, n. 3, p. 369-392, 2010.

PÔRTO JÚNIOR, S.; RIBEIRO, E. P. Dinâmica espacial da renda per capita e crescimento entre os municípios da região nordeste do Brasil: uma análise markoviana. Revista Econômica do Nordeste, Fortaleza, v. 34, n. 3, p. 405-420, 2003.

QUAH, D. Galton's fallacy and tests of the convergence hypothesis. The Scandinavian Journal of Economics, v. 95, n. 4, p. 427-443, Dec. 1993.

RIBEIRO, L. C. et al. National systems of innovation and technological differentiation: a multi-country model. International Journal of Modern Physics C, v. 17, n. 2, p. 247-257, 2006a.

RIBEIRO, L. C. et al. Science in the developing world: running twice as fast? Computing in Science $\mathcal{E}$ Engineering, v. 8, n. 4, p. 81-88, 2006b.

RODRIK, D. The past, present, and future of economic growth. [S. 1.]: Global Citizen Foundation, 2013. (Working paper 1, June 2013). 
ROMERO, J. P.; JAYME JÚNIOR, F. G. Financial system, innovation and regional development: the relationship between liquidity preference and innovation in Brazil. Review of Political Economy, v. 24, n. 4, p. 623-642, 2012.

ROMERO, J. P.; JAYME JÚNIOR, F. G. Sistema financeiro, inovação e desenvolvimento regional: um estudo sobre a relação entre preferência pela liquidez e inovação no Brasil. Belo Horizonte: UFMG/CEDEPLAR, 2009. (Texto para discussão nº 357).

SANTOS, E. C. C. Papel do Estado para o desenvolvimento do SNI: lições das economias avançadas e de industrialização recente. Economia e Sociedade, Campinas, v. 23, n. 2, p. 433-464, ago. 2014.

TAHA, H. A. Pesquisa operacional. 8. ed. São Paulo: Pearson Education do Brasil, 2008.

TAUCHEN, G. Finite state markov-chain approximations to univariate and vector autoregressions. Economics Letters, v. 20, n. 2, p. 177-181, 1986.

UNITED STATES OF AMERICA. United States Patent and Trademark Office. Database. Washington, D. C., 2012. Disponível em: <https://ped.uspto.gov/peds/>. Acesso em: 12 maio 2015.

WORLD BANK. World Bank indicators online. Washington, D. C., 2010. Disponível em: <http://databank.worldbank.org/data/reports.aspx?source=world-developmentindicators $>$. Acesso em: 4 maio 2015. 


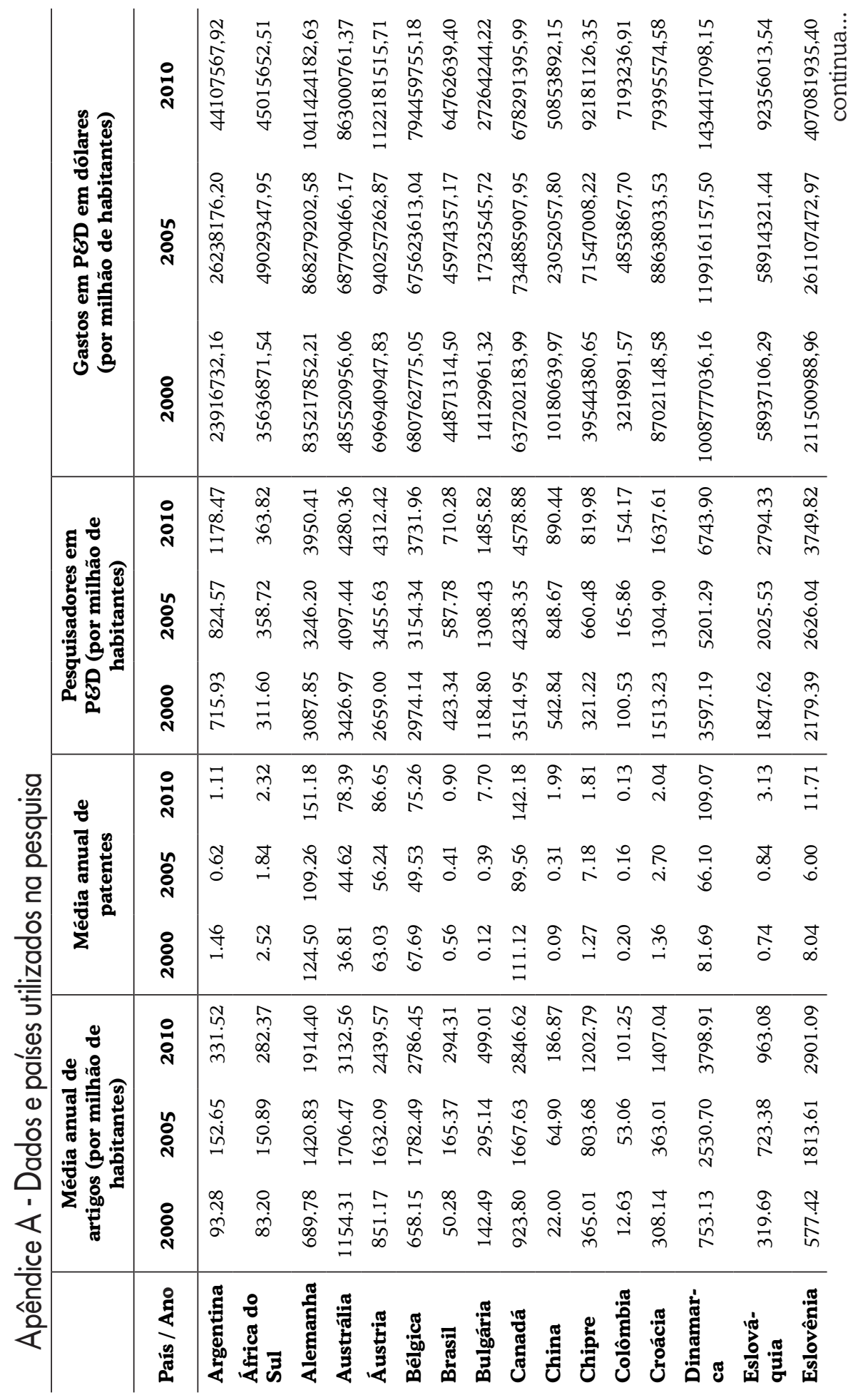




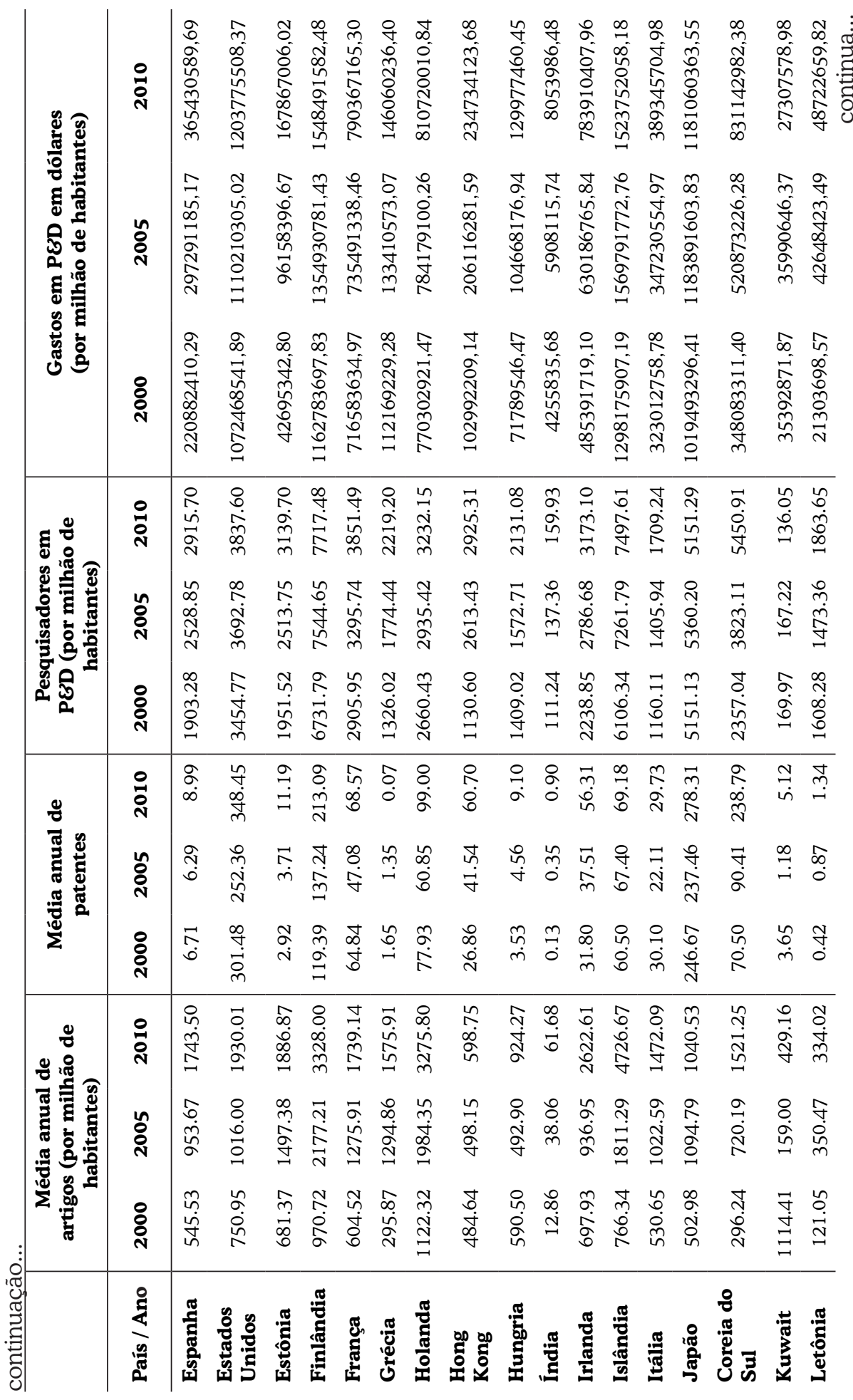
Análise Econômica, Porto Alegre, v. 36, n. 70, p. 121-148, jun. 2018. 


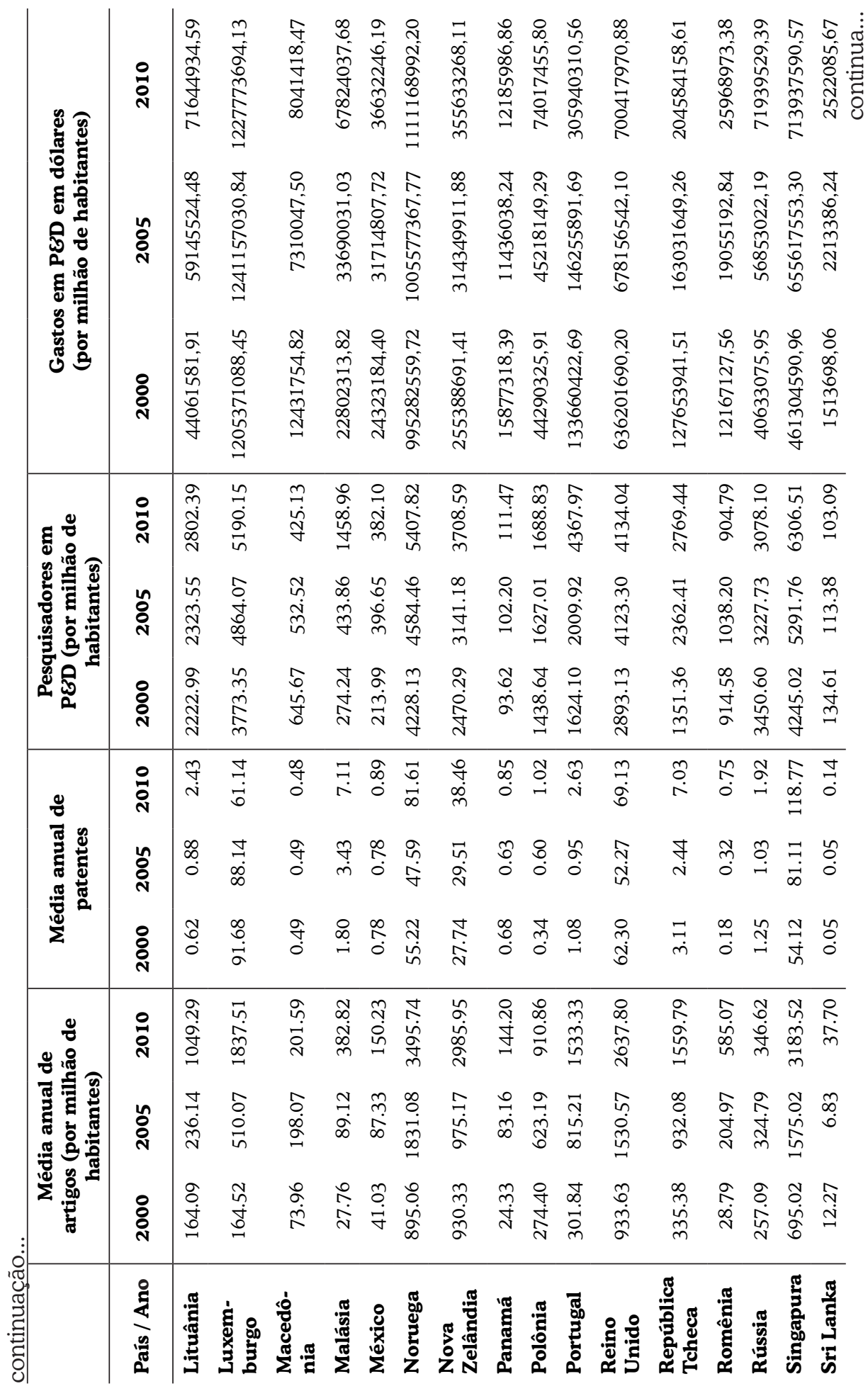




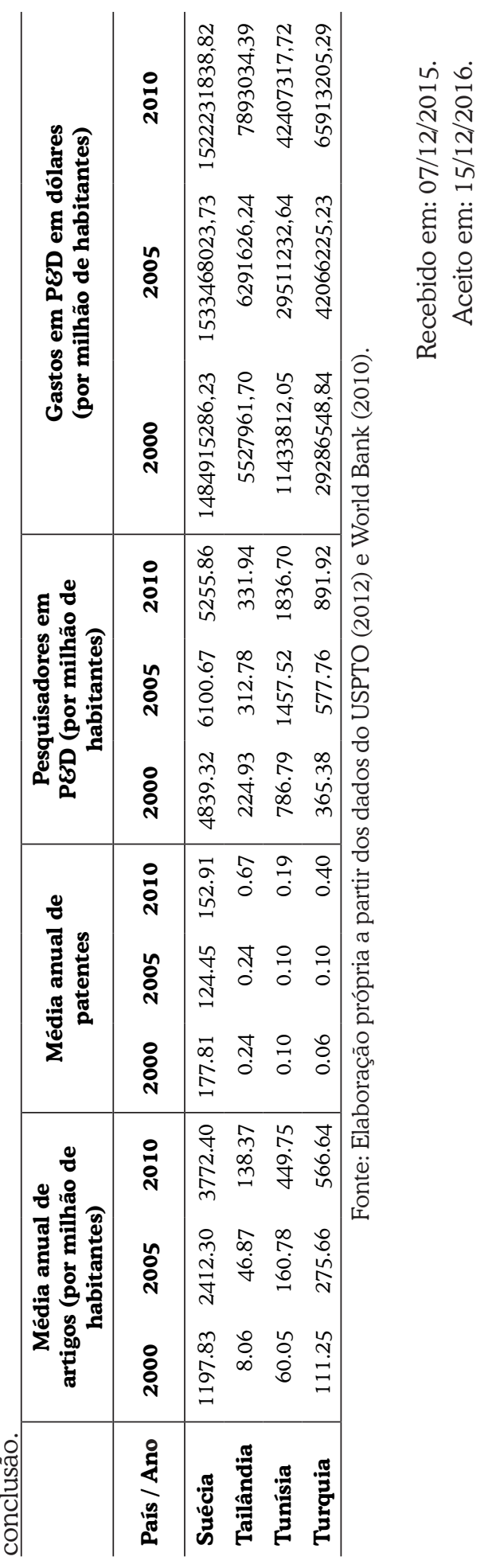

